\title{
Growth dynamics and education spending: The role of inherited tastes and abilities
}

\author{
David de la Croix* \\ IRES, Université catholique de Louvain, Place Montesquieu 3, B-1348 Louvain-la-Neuve, Belgium \\ National Fund for Scientific Research, Brussels, Belgium
}

Received 1 February 1998; accepted 1 January 2000

\begin{abstract}
We present an overlapping generations model with endogenous growth in which children inherit human capital and standard-of-living aspirations from the previous generation. Adults evaluate their own consumption with respect to a baseline-requirement which depends on their parents' past consumption. The interaction between these two intergenerational externalities leads to rich dynamics. First, starting with too high aspirations or with too low human capital will conduct the economy into a poverty trap. Second, the growth rate and the savings rate are characterized by oscillations. Third, a repelling cycle may delimit a basin of attraction around the balanced growth path: this may lead countries starting with too high human capital to a boom followed by an irreversible decline. (C) 2001 Elsevier Science B.V. All rights reserved.
\end{abstract}

JEL classification: E32; O41

Keywords: Endogenous growth; Human capital; Aspirations; Poverty trap; Limit cycle

\section{Introduction}

In a growing economy, each generation normally has more resources at its commands on reaching adulthood. These additional resources result on the one

\footnotetext{
* Tel.: 0032-10-47-34-53; fax: 0032-10-47-39-45.

E-mail address: delacroix@ires.ucl.ac.be (D. de la Croix).
} 
hand from the increase in productivity linked to the accumulation of physical capital by the previous generation. On the other hand, they result from the accumulation of human capital as children inherit knowledge and skills from their parents and enhance their bequeathed abilities by training and education. In that case, education is an important factor of economic growth and the intergenerational knowledge spill-overs are essential to economic development. This is consistent with the large fraction of growth attributed to improvements in the quality of labor services (see Denison, 1974; Goldin, 1994; Nehru et al., 1995). In such a framework, the crucial element for explaining permanent endogenous development ${ }^{1}$ is the presence of a positive externality that makes individual-specific human capital increasing in aggregate human capital (Lucas, 1988; Azariadis and Drazen, 1990) and/or in the human capital of the previous generation (Michel, 1993).

However, as stressed by Easterlin (1971), income growth from one generation to another is a two-edged sword. His argument is that in a steadily growing economy, successive generations are raised in increasingly affluent households and hence develop successively higher living aspirations'. This 'intergenerational taste effect' is a negative externality making the future generations more and more demanding along the growth process. This is dramatically illustrated by the results of a survey of the experience in a rapidly growing economy - Taiwan - analyzed by Freedman (reported by Easterlin, 1974): 'Only 20 percent of the respondents said their financial position had improved during the last five years, although real per capita income increased about 40 percent during that period'.

How these two externalities interact seems an important topic for long-run development. Indeed, the interaction of inherited higher skills and higher aspirations could explain why development and economic growth are not as successful and widespread as the standard theory predicts. For instance, if aspirations are rising too fast compared to productivity, households could be tempted to lower savings and/or education spending in order to maintain the growth of their consumption. Could this behavior slow down the accumulation of human capital, lead to stagnation and be responsible for poverty traps? Moreover, if long-term growth is not steady but fluctuating, temporary disparities may result between the growth of resources and that of aspirations with consequent swings in utility. What is the consequence of these swings on the optimal plans of the households and on the ability of an economy to reach a balanced growth path?

The paper is organized as follows. In Section 2 we discuss the importance of intergenerational taste effect transmission for growth. We next build a small prototype model including both types of intergenerational spill-overs (Section 3) and analyze its dynamic properties (Section 4). The discussion on the novel

\footnotetext{
${ }^{1}$ And hence the observed lack of unconditional convergence in per capita income at the world-wide level (Barro, 1991).
} 
implications of the model is proposed in Section 5. Conclusions are drawn in Section 6.

\section{Intergenerational taste externalities}

Parents' influence on children is not limited to resource transfers or human capital transfers. Becker (1992) notices that 'The habits acquired as a child or young adult generally continue to influence behavior even when the environment changes radically. For instance, Indian adults who migrate to the United States often eat the same type of cuisine they had in India, and continue to wear the same type of clothing. (...) Childhood-acquired habits then continue, even though these would not have developed if the environment when growing up had been the same as the environment faced as an adult. (... )' A comprehensive survey of evidence of vertical transmission (i.e. from parents to children), including the fear of insects and also career aspirations, is provided in Boyd and Richerson (1985). These vertical transmission mechanisms are modelled in different strands of literature. All of them lead to the conclusion that intergenerational taste externalities are particularly important for thinking about long-term evolution processes like growth.

\subsection{Habit formation}

The involuntary transmission of tastes from one generation to the next has, as far as we know, not been formalized in economics. ${ }^{2}$ Besides its intergenerational aspect, the idea of bequeathed tastes reflects the effect of past decisions on the perception of current outcomes. In the context of consumption, this clearly refers to the models of habit formation initiated by Duesenberry (1949) and developed afterwards by many others. The empirical studies in this literature have always been developed in the framework of infinitely lived agents (or dynasties of altruistic agents). They often find strong support in favor of time non-separable preferences (for a recent study see de la Croix and Urbain, 1998). Moreover, there is convincing experimental support for supposing a habituation mechanism by which the most salient events are progressively absorbed into the new baseline against which further events are judged (see Brickman et al., 1978). Finally, as studied by de la Croix (1998), one empirical implication of the habit formation models is that reported satisfaction levels do not necessarily increase over time in line with economic development. This is consistent with the

\footnotetext{
${ }^{2}$ One exception is Jones (1984) who analyses traditions of behavior within the context of a workplace. Jones analyses a model in which it is through conformism between neighboring generations that we generate traditions passed down from one generation to the next'.
} 
empirical evidence provided by Easterlin (1995). The fact that 'an Indian will, on average, be twice as well off as his grandfather' (Lucas, 1988) does not mean that his satisfaction level has increased, as standard-of-living norms will have risen too.

\subsection{Social capital}

The intergenerational spill-over can take the form of what social scientists call social capital. Following Coleman (1990), physical capital is wholly tangible, being embodied in equipment; human capital is embodied in the individuals through skills and knowledge; social capital is embodied in the relations among persons. The family relationships are important vectors of social capital allowing for intergenerational spill-overs. Chapter 22 of Coleman (1990) analyses how different family structures generate social capital and how the decline in the role of the family in recent decades can be important for the social capital of the next generations. In Coleman (1990), social capital can be seen as a vector of growth; he does not investigate situations in which some sort of social capital can hamper the growth process.

\subsection{Cultural transmission}

The most comprehensive analysis of intergenerational spill-overs can be found in the work of Cavalli-Sforza and Feldman (1981) Boyd and Richerson (1985). They study cultural transmission across generations, and in particular, the link between the transmission of culture and the transmission of genes.

After having assessed the huge importance of social learning within the family, Boyd and Richerson (1985) build different models in which the distribution of beliefs, attitudes and values in a population are transmitted and modified. The most important source of ambiguity is the empirical difficulty to disentangle cultural inheritance from genetic inheritance. However, linking the models of cultural transmission to models of genetic evolution helps to determine the circumstances under which natural selection might favor the modes of cultural transmission observed among human beings. Given detailed assumptions about the structure of cultural transmission and the nature of the environment, they predict the kinds of culturally transmitted behaviors that should characterize a particular population.

In Cavalli-Sforza and Feldman (1981), the vertical transmission of culture is measured using the Stanford survey of beliefs and values. Vertical transmission appears clearly important concerning four items (dietary habits, religious habits, sports participation and political interest) among five. The authors next study the interaction between the inheritance of culture, the inheritance of genes and the environment. One interesting aspect is that cultural selection is distinguished from natural selection. Cultural selection is determined by the acceptance or 
refusal by the individual after his exposure to the trait. Cultural selection is important to determine the type of dynamics that can emerge. For instance, negative reactions to examples set by parents may generate cyclical dynamics. Once cultural selection has occurred, the Darwinian fitness of the trait is tested. Indeed, the inheritance of a trait can alter the viability of the next generation, depending on how this trait 'fits' with the process of natural selection. This can lead to unstable dynamics, and to the extinction of some traits.

\subsection{Modelling intergenerational taste externalities}

In a simple general equilibrium model, intergenerational taste externalities may be modelled in the following way. Denoting by $u($.) the instantaneous utility of an adult, the influence of parents could be introduced by assuming that $u$ depends both on the own consumption of the agent $c_{t}$ and on a state variable $a_{t}$ which itself depends on his parents' past consumption. We thus have $u\left(c_{t}, a_{t}\right)$ and we may distinguish two cases depending on the sign of the intergenerational spill-over.

When $u_{a}^{\prime}>0$, the consumption of the parents has a positive influence on the utility of their children. This is the case, for instance, when the children learn an 'art-of-living' with their parents; this stock of cultural knowledge presents some durability and still exerts a positive influence when the children become adults. The effect of $a$ on the consumption behavior of the new adult depends on $u_{c a}^{\prime \prime}$. If $u_{c a}^{\prime \prime}<0$, the desire to consume is reduced by the stock of cultural knowledge, when for instance the agents have learned how to withdraw a maximum satisfaction from what they consume, and we say that they are repleted. If $u_{c a}^{\prime \prime}>0$ the desire of consumption is increasing with the parents' consumption and we say that there is addiction.

When $u_{a}^{\prime}<0$, which is the case studied in this paper, parents' consumption has a negative influence on children's utility. As in the psychological models of the 'goal - achievement gap' (Michalos, 1980), the instantaneous satisfaction depends on the gap between the actual consumption and the aspirations, i.e. the consumption of the previous generation. If $u_{c a}^{\prime \prime}<0$, the aspiration effect generates distaste. If $u_{c a}^{\prime \prime}>0$, which is the interesting case, the aspirations serve as a benchmark consumption level determining a goal to reach for the new generation. They induce a desire of catching-up, pushing the new generation to consume more than what their parents did. The utility function used in the sequel will display this catching-up effect.

\section{The model}

The model is an extension in two directions of the basic example of a Diamond (1965) economy without outside money. On the one hand, human 
capital accumulation is introduced to account for endogenous growth. In the growth process, a part of the human capital is transmitted from the parents to their children. On the other hand, children inherit standard-of-living aspirations from their parents.

\subsection{The households' life cycle}

Time is discrete and goes from 0 to $+\infty$. In each period, the economy is populated by three generations, each living for three periods. The growth rate of the population is zero and the size of a generation is 1 . At each date a single good is produced. This good can be either consumed during the period, accumulated as capital for future production or spent on education. At time $t-1$, the young generation does not consume but spends $e_{t-1}$ in order to improve its stock of human capital. This amount is borrowed on the capital market. The productivity of this private education spending is a positive function of (a) the stock of human capital of the parents $h_{t-1}$ and of (b) the per capita public spending on education $g_{t-1}$. The human capital of this generation is given by ${ }^{3}$

$$
h_{t}=\psi g_{t-1}^{\lambda} h_{t-1}^{1-\beta-\lambda} e_{t-1}^{\beta}, \quad \psi>0, \beta, \lambda \in[0,1[.
$$

This equation reflects the fact that the young generation inherits a part of its parents' human capital. This bequest is the engine to endogenous growth in the model. ${ }^{4}$ Public spending on education is exogenous. ${ }^{5}$

The young generation born in $t-1$ also inherits aspirations that are based on the standard-of-living reached in $t-1$ by the previous generation (born in $t-2$ ). Its aspirations at time $t$ are thus

$$
a_{t}=c_{t-1} .
$$

The adult generation sells $h_{t}$ units of efficient labor inelastically at a real wage $w_{t}$, pays back its debt linked to education spending and pays lump-sum taxes to finance the public education spending. Its disposable income is thus

$$
\Omega_{t}=h_{t} w_{t}-R_{t} e_{t-1}-g_{t},
$$

where $R_{t}=1+r_{t}$ is the interest factor. Income is used to consume the quantity $c_{t}$ and save $s_{t}$ for next period consumption by holding capital. The budget

\footnotetext{
${ }^{3}$ See Hercowitz and Sampson (1991) for a discussion of a similar rule for physical capital.

${ }^{4}$ The log-linear formulation amounts to assuming that three elements that build human capital are necessary: a society without public or private spending or without cultural background cannot reach a positive level of human capital.

${ }^{5}$ An alternative explored in de la Croix and Monfort (2000) in a related model is to assume a voting procedure.
} 
constraint of the adult is

$$
c_{t}+s_{t}=\Omega_{t} .
$$

The old generation spends all its savings from the previous period and consumes $d_{t+1}$,

$$
d_{t+1}=R_{t+1} s_{t}
$$

The intertemporal utility of the typical adult has a specific functional form of the logarithmic type:

$$
u\left(c_{t}, a_{t}, d_{t+1}\right)=\theta \ln \left(c_{t}-\gamma a_{t}\right)+(1-\theta) \ln \left(d_{t+1}\right) .
$$

$\theta \in] 0,1[$ is a parameter of the utility function and $\gamma \in] 0,1[$ measures the intensity of the effect of the intergenerational spill-over. Bequeathed tastes determine a frame of reference against which consumption when adult is judged. As $u_{c a}^{\prime \prime}>0$, the aspiration effect induces a desire of catching-up, pushing the new generation to consume more than what their parents did. We also assume that the depreciation rate of aspirations (i.e. forgetting) is high so that they no longer affect the evaluation of consumption when old. This simplifying assumption proxies the idea that aspirations are less important for older persons. ${ }^{6}$

A typical adult faces the following problem:

$$
\begin{aligned}
& \max _{e_{t-1}, s_{t}} u\left(c_{t}, a_{t}, d_{t+1}\right) \\
& \text { s.t. (1)-(6), } \\
& c_{t} \geq \gamma a_{t}, \quad d_{t+1} \geq 0 .
\end{aligned}
$$

The variables $h_{t-1}, w_{t}, R_{t}, R_{t+1}, g_{t-1}$ and $a_{t}$ are given to the consumer. The consumer chooses education spending $e_{t-1}$ when young, and savings $s_{t}$ when adult. We thus solve the problem backward.

Step 2: When adult, the consumer chooses $s_{t}$ given the level of $e_{t}$. Assuming an interior solution, this decision problem has a unique solution characterized by the following savings function:

$$
s_{t}=(1-\theta)\left(\Omega_{t}-\gamma a_{t}\right)
$$

\footnotetext{
${ }^{6}$ This is supported by the empirical observation that reported satisfaction increases from the age of 30 onwards. On the basis of their empirical study on job satisfaction, Clark et al. (1996) conclude that 'the rise in job satisfaction at these ages could come from reduced aspirations, due to a recognition that there are few alternative jobs available once a worker's career is established (...). Alternatively, aspirations themselves could remain the same but older workers might put less weight on such comparisons $(\ldots)$ '.
} 
Savings do not depend on the interest factor $R_{t+1},{ }^{7}$ because of the specific form of the utility function, as there is no wage income in the last period of life and as aspirations are fully forgotten after one period. We thus avoid the potential negative effect of the interest rate on savings as a source of complex dynamics. Eq. (7) shows also that aspirations affect savings negatively. When aspirations are low, the adult generation has a sober lifestyle and savings are high. When aspirations are high compared to wage income, adults spend much on consumption to maintain a standard-of-living similar to the one of their parents and their propensity to save is low. Using (7) and the household budget constraint, consumption when adult is given by

$$
c_{t}=\frac{\theta}{1-\theta} s_{t}+\gamma a_{t} \text {. }
$$

The indirect utility function is given by $v_{t} \propto \Omega_{t}-\gamma a_{t}$.

Step 1: When young, the consumer chooses $e_{t}$ that maximizes indirect utility subject to the accumulation rule of human capital (1). The first-order condition leads to

$$
e_{t-1}=h_{t-1}^{(1-\lambda-\beta) /(1-\beta)}\left(\beta \psi g_{t-1}^{\lambda} \frac{w_{t}}{R_{t}}\right)^{1 /(1-\beta)} .
$$

Spending on education depends positively on the future wage per unit of efficient labor $w_{t}$ and negatively on the interest rate applied to their loan. Due to the specific functional forms used, it does not depend directly on life cycle aspirations, which simplifies the analysis substantially. ${ }^{8}$

\subsection{The firms}

Production is made through a Cobb-Douglas constant returns to scale technology. Physical capital is assumed to be fully depreciated after one period. The profits of the firms are given by

$$
\left.K_{t}^{\alpha} h_{t}^{1-\alpha}-w_{t} h_{t}-R_{t} K_{t}, \quad \alpha \in\right] 0,1[\text {. }
$$

The production function in intensive form is thus $y_{t}=k_{t}^{\alpha}$ with $k_{t}=K_{t} / h_{t}$, in which $y_{t}$ is the output per efficient unit of labor. The competitive behavior of firms leads to the equalization of the marginal productivity of each factor to

\footnotetext{
${ }^{7}$ Note however that, since $e_{t}$ is borrowed on the financial market, the current interest factor $R_{t}$ does affect savings.

${ }^{8}$ However, note that parents' aspirations may affect education spending of their children negatively by reducing savings and increasing the interest rate.
} 
its cost:

$$
\begin{aligned}
& w_{t}=(1-\alpha) k_{t}^{\alpha}, \\
& R_{t}=\alpha k_{t}^{\alpha-1} .
\end{aligned}
$$

Replacing in (9) the factor prices by their values given by (10) and (11), the choice of education spending satisfies

$$
k_{t}=\frac{\alpha / \beta}{1-\alpha} \frac{e_{t-1}}{h_{t}} .
$$

This implies that there is a linear relationship between the capital intensity and the private education spending per unit of human capital. ${ }^{9}$ Using (10)-(12) in (3) and (7) and defining a parameter $\mu=(1-\alpha)^{1-\alpha}(\alpha / \beta)^{\alpha}(1-\beta)$, we rewrite optimal savings as

$$
s_{t}=(1-\theta)\left[\mu h_{t}^{1-\alpha} e_{t-1}^{\alpha}-\gamma a_{t}-g_{t}\right] .
$$

\subsection{The capital market}

The clearing condition of the capital market implies that savings are equal to investment in physical and human capital:

$$
s_{t}=K_{t+1}+e_{t} .
$$

Using (12) and defining $v=1 /(1-\theta)((\alpha / \beta) /(1-\alpha)+1)$, (14) can be rewritten as

$$
s_{t}=v(1-\theta) e_{t} .
$$

\section{The equilibrium}

The dynamics of this economy can be summarized by two difference equations of the first order. First, equating (13) and (15) and dividing both sides by $h_{t}$, we find

$$
\nu \frac{e_{t}}{h_{t}}=\mu\left(\frac{e_{t-1}}{h_{t}}\right)^{\alpha}-\gamma \frac{a_{t}}{h_{t}}-\frac{g_{t}}{h_{t}} .
$$

Given that the labor market is in equilibrium, i.e. that (10) holds, (16) is the clearing condition of the asset market. Second, using (2), (8) and (13), and

\footnotetext{
${ }^{9}$ The relationship between the capital intensity and the private education spending per unit of human capital is linear thanks to the assumption of a unit depreciation rate of capital.
} 
dividing both sides by $h_{t}$ we obtain

$$
\frac{a_{t+1}}{h_{t}}=\theta \mu\left(\frac{e_{t-1}}{h_{t}}\right)^{\alpha}+(1-\theta) \gamma \frac{a_{t}}{h_{t}}-\theta \frac{g_{t}}{h_{t}} .
$$

(17) is the aspiration rule given that the other markets are in equilibrium.

Let us define stationary variables $\hat{a}_{t} \equiv a_{t} / h_{t-1}, \hat{g}_{t} \equiv g_{t} / h_{t}$ and $\hat{e}_{t} \equiv e_{t-1} / h_{t-1}$ and assume for simplicity that $\hat{g}_{t}$ is constant and equal to $\hat{g}$. Growth depends on $\hat{e}_{t}$ and $\hat{g}$ :

$$
\frac{h_{t}}{h_{t-1}}=\psi(\hat{g})^{\lambda}\left(\hat{e}_{t}\right)^{\beta} \equiv x\left(\hat{e}_{t}, \hat{g}\right)
$$

We now define the equilibrium as follows. At date 0 , the economy is endowed with a fixed quantity of education spending per unit of human capital $\hat{e}_{0}$ and a level of aspirations per unit of human capital $\hat{a}_{0}$. A perfect foresight equilibrium is a sequence $\left(\hat{e}_{t}\right)_{t \geq 0},\left(\hat{a}_{t}\right)_{t \geq 0}$ verifying at each date $t \geq 0$

$$
\begin{aligned}
& \hat{e}_{t+1}=\frac{\mu \hat{e}_{t}^{\alpha}}{v x\left(\hat{e}_{t}, \hat{g}\right)^{\alpha}}-\frac{\gamma \hat{a}_{t}}{v x\left(\hat{e}_{t}, \hat{g}\right)}-\frac{\hat{g}}{v}, \\
& \hat{a}_{t+1}=\frac{\theta \mu \hat{e}_{t}^{\alpha}}{x\left(\hat{e}_{t}, \hat{g}\right)^{\alpha}}+\frac{(1-\theta) \gamma \hat{a}_{t}}{x\left(\hat{e}_{t}, \hat{g}\right)}-\theta \hat{g} .
\end{aligned}
$$

Before considering the general model let us first analyze two simple cases. In case 1 , the intergenerational taste externality is removed $(\gamma=0)$ in order to study more easily the role of the human capital externality taken in isolation. In case 2 , we consider the model with an exogenous human capital stock $(\lambda=\beta=0)$ and focus our attention on the effect of the taste externality in an otherwise standard overlapping generations model. We next combine the two externalities and analyze the more complex model.

\subsection{The model without taste externality}

When $\gamma=0$, there is no intergenerational spill-over due to aspirations, and the model is similar to the one presented in Michel (1993) to which public spending on education has been added. The dynamics of the economy is characterized by one difference equation:

$$
\hat{e}_{t+1}=\frac{\mu \hat{e}_{t}^{\alpha}}{v x\left(\hat{e}_{t}, \hat{g}\right)}-\frac{\hat{g}}{v} .
$$

This equation defines a transition function in the space $\left\{\hat{e}_{t+1}, \hat{e}_{t}\right\}$ which is increasing and concave. This function is represented in Fig. 1 for two different values of $\hat{g}_{t}$. Since the function tends to $-\infty$ when $e_{t}$ tends to zero, and since it is concave, the economy can have zero, one or two stationary states, depending 

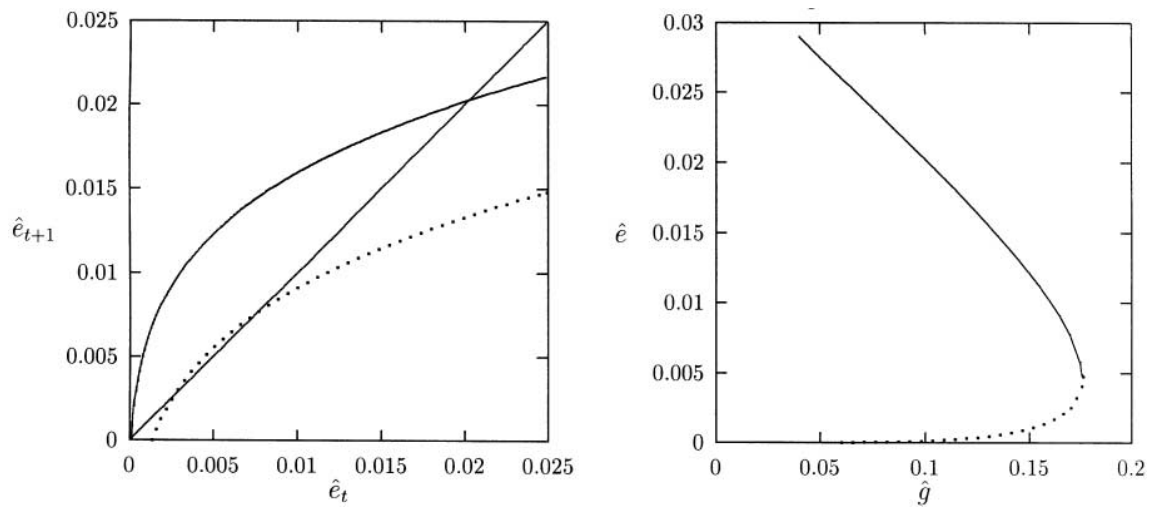

Fig. 1. The transition function and the bifurcation diagram when $\gamma=0$.

on the location of the transition function with respect to the $45^{\circ}$ line. When there are two stationary states, the higher one is always stable whilst the lower one is unstable.

The ratio of public education spending on education to human capital, $\hat{g}$, is crucial to determine the location of the transition function. When $\hat{g}$ (and hence taxes) increases, the agents will lower their private spending on education since their disposable income has been reduced. This shifts the transition function down as shown on the left panel of Fig. 1. To describe the effect of public spending on the economy, we present the corresponding bifurcation diagram in the right panel of Fig. 1: it shows the different stationary state values of $\hat{e}$ as a function of $\hat{g}$, the other parameters being given. The continuous line represents the stable stationary states, the dotted line the unstable stationary states. When $\hat{g}$ increases, the two stationary states move closer to the saddle-node bifurcation point. At this point, the transition function is tangent to the $45^{\circ}$ line. After this point, there is no positive stationary state: taxes are so high that households do not spend any money on education and the human capital stock tends to zero.

If we now consider the effect of public spending on growth, we find that the total effect results from two components: ${ }^{10}$ the favorable one is the efficiency gain in the accumulation of human capital and the negative one is linked to the reduction in savings caused by taxation. Fig. 2 illustrates the effect of public spending on the growth rate of the human capital stock (see Eq. (18)). For the parameters we have chosen, we see that there is a growth-maximizing level of public spending. After this point, increasing public spending reduces growth, as

${ }^{10}$ Compare with Barro (1990) in which public spending affects the production function directly. 


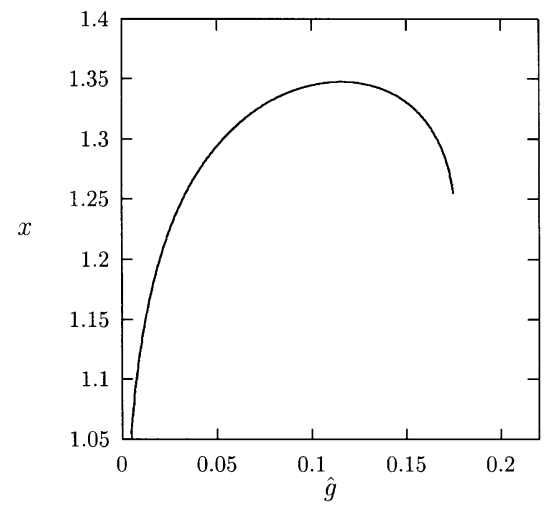

Fig. 2. Growth and public spending.

the tax effect dominates the efficiency effect on the accumulation of human capital.

\subsection{The model without human capital externality}

When $\lambda=\beta=0$ and $\psi=1$ the human capital stock is a constant, there is no endogenous growth. This simple Diamond economy with bequeathed tastes is analyzed in de la Croix (1996). In that case, the dynamic system redefined in terms of $k$ and $a$ has two fixed points, one at $(0,0)$ and another at $(\bar{k}(\gamma), \bar{a}(\gamma))$, which depends on the parameter of interest $\gamma$ and is defined by

$$
\begin{aligned}
& \bar{k}(\gamma)=\left(\frac{(1-\theta)(1-\alpha)(1-\gamma)}{1-\gamma(1-\theta)}\right)^{1 /(1-\alpha)}, \\
& \bar{a}(\gamma)=(1-\alpha) \bar{k}^{\alpha}-\bar{k} .
\end{aligned}
$$

As $\partial \bar{k} / \partial \gamma<0$ holds, the stationary capital stock per head is lower in the economy with bequeathed tastes than in the standard Diamond economy. This is essentially due to the negative effect of aspirations on savings. Moreover, the fixed point $(\bar{k}(\gamma), \bar{a}(\gamma))$ is stable if $\gamma<\hat{\gamma}$ and unstable if $\gamma>\hat{\gamma}$ where

$$
\hat{\gamma}=\frac{1+\alpha-\sqrt{(1+\alpha)^{2}-4 \alpha(1-\theta)}}{2 \alpha(1-\theta)} .
$$

Hence, if the effect of aspirations on utility is strong enough, this makes the fixed point unstable. In addition, the eigenvalues of the linearized system are complex conjugates for large intervals of the parameters. The dynamics around the positive fixed point are thus characterized by oscillations. When we analyze 
the properties of the model when $\gamma$ varies, it is possible to establish that a Naimark-Sacker ${ }^{11}$ bifurcation arises at $\gamma=\hat{\gamma}$. This bifurcation is characterized by two complex eigenvalues having a modulus equal to 1 . In a neighborhood of the bifurcation point, a limit cycle around $(\hat{k}, \hat{a})$ appears either on the low or on the high side of the critical parameter value. In addition, it is analytically not possible (in our case) to check whether the limit cycle appears on the unstable side of the fixed point and is attracting or whether it encircles the fixed point on the stable side and is repelling. Numerical simulations show however that the limit cycle appears here on the stable side of the steady state and delimits its basin of attraction. If the initial condition on $\{k, a\}$ is inside the cycle, the economy will converge with damped oscillations. If the initial condition on $\{k, a\}$ is outside the circle, the trajectory will explode.

The economic rationale for oscillations in this case is the following: The spill-over from one generation to the next has two components: (a) savings of the old generation finance the capital stock required to produce and to pay the wages of the young generation; this process that transforms income/savings of the old into income for the young displays decreasing returns; (b) past consumption levels of the parents generate standard-of-living aspirations for the young generation, leading them to spend more on consumption; this process displays constant returns. At one point, due to the decreasing returns in the production process, the bequest in terms of higher wages is not sufficient to cover the bequest in terms of higher aspirations. This leads to a drop in savings to maintain the standard-of-living and induces a recession. When the consecutive impoverishment is strong enough, aspirations revert to lower levels, allowing a rise in savings and the start of an expansion period. Depending on the relative strength of the two effects and on the current state of the economy compared to its stationary state, this process can either converge, or explode.

Note finally that, in another paper (de la Croix and Michel, 1999), we study the policy that should be implemented to internalize the 'taste' externality and hence avoid or reduce the fluctuations. This policy amounts to subsidize savings, in addition to the usual public intergenerational transfers. This allows to equalize the return on saving to its social value and therefore take into account the effect of parents' consumption on children's habits.

\subsection{General case}

After having studied the two externalities in isolation, we now consider the general case with both $\gamma>0$ and $\beta>0$. We represent the dynamics of the model by drawing its phase diagram. We may first note that the constraint $c_{t} \geq \gamma a_{t}$ is

\footnotetext{
${ }^{11}$ This bifurcation is often called 'Hopf bifurcation for maps'. See Wiggins (1990) for a complete characterization.
} 

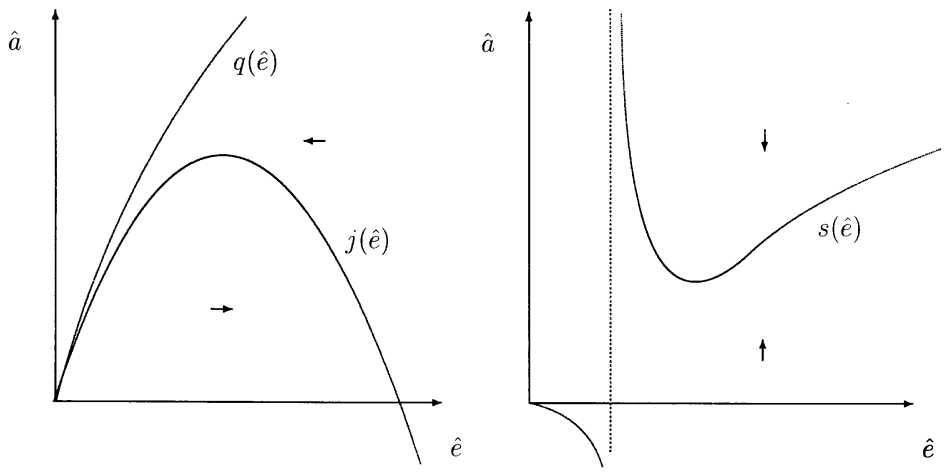

Fig. 3. The phase-lines.

necessary for an interior solution. This constraint can be rewritten $\hat{a}_{t+1} \geq \gamma \hat{a}_{t} / x\left(\hat{e}_{t}, \hat{g}\right)$. Using the difference equation (20), we obtain

$$
\hat{a}_{t} \leq \frac{\mu \hat{e}_{t}^{\alpha} x\left(\hat{e}_{t}, \hat{g}\right)^{1-\alpha}-\hat{g} x\left(\hat{e}_{t}, \hat{g}\right)}{\gamma} .
$$

The right-hand side of (22) defines a monotonous increasing function $q(\hat{e}) . q($.$) is$ concave and has an infinite slope at the origin. The function $\hat{a}=q($.$) is represent-$ ed in the left panel of Fig. 3.

Second, using (19) the phase-line corresponding to $\hat{e}_{t+1}=\hat{e}_{t}$ can be written as

$$
\hat{a}_{t}=\frac{\mu \hat{e}_{t}^{\alpha} x\left(\hat{e}_{t}, \hat{g}\right)^{1-\alpha}-\hat{g} x\left(\hat{e}_{t}, \hat{g}\right)-v \hat{e}_{t} x\left(\hat{e}_{t}, \hat{g}\right)}{\gamma} .
$$

This defines a function $\hat{a}=j(\hat{e})$. This function satisfies $j(x)<q(x)$ for all $x \geq 0$, that $j($.$) is concave, continuous, has an infinite slope at the origin and decreases$ unboundedly when $\hat{e} \rightarrow \infty$.

Third, the phase-line corresponding to $\hat{a}_{t+1}=\hat{a}_{t}$ can be written using (20) as

$$
\hat{a}_{t}=\frac{\theta \mu \hat{e}^{\alpha} x\left(\hat{e}_{t}, \hat{g}\right)^{1-\alpha}-\theta \hat{g} x\left(\hat{e}_{t}, \hat{g}\right)}{x\left(\hat{e}_{t}, \hat{g}\right)-(1-\theta) \gamma} .
$$

This defines a function $\hat{a}=s(\hat{e})$. This function has a vertical asymptote at $\hat{e}$ such that $x\left(\hat{e}_{t}, \hat{g}\right)=(1-\theta) \gamma$. It is negative between 0 and the asymptote and positive thereafter. $s($.$) reaches a minimum on the right-hand side of the asymptote, and$ starts increasing unboundedly after it.

These pieces of information are gathered in Fig. 3 in which the arrows indicate the direction of motion. From this figure it appears that our qualitative analysis is not sufficient to determine whether the two phase-lines intersect twice, are 


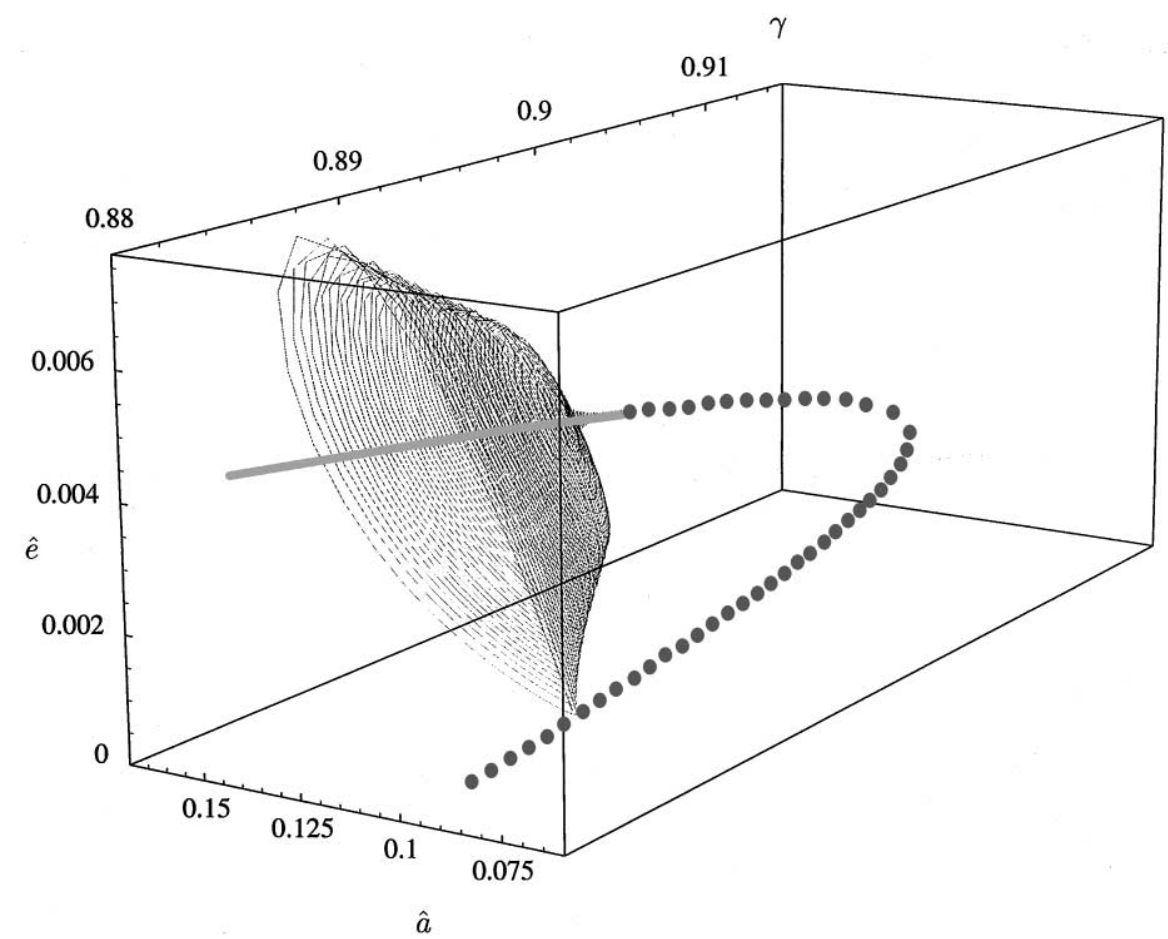

Fig. 4. The bifurcation diagram in the general case.

tangent or do not intersect at all. This depends crucially on the different parameters.

To further characterize the dynamics of the model we have thus to rely on numerical methods applied to a parametrized example of the model. We adopt a strategy that consists in using what we view as plausible parameter values and then tracing the associated equilibrium trajectories using numerical methods. We use the following suggestive values: $\alpha=1 / 4, \theta=0.6, \beta=0.1, \lambda=0.1$, $\hat{g}=0.07, \psi=2.5$. These values have been chosen to give reasonable ratios $(c+d) / y, e / y, g / y, R, x($.$) . We have imposed the equality between \beta$ and $\lambda$ so as to give the same elasticity of human capital to both types of education spending. Note that the value for $\alpha$ gives a human capital share in value-added of $75 \%$ and that the value of $1-\beta-\gamma$ gives a prominent role to the intergenerational spill-over.

We now analyze the effect of the parameter of interest, $\gamma$ on the equilibrium. Fig. 4 presents the bifurcation diagram for this parameter in the space $\{\hat{e}, \hat{a}, \gamma\}$. Starting with a low $\gamma$, we have two positive stationary states. The lower stationary state is locally unstable (dots); the higher stationary state is locally 
stable (solid line). The computation of the eigenvalues of the linearized system indicates that as long as $\gamma$ is lower than 0.897 the high stationary state is stable. The dynamics display damped oscillations since the eigenvalues are complex with a modulus lower than 1 . When $\gamma=0.897$ the system is subject to a Naimark-Sacker bifurcation, at which the modulus of the complex conjugate eigenvalues is 1 . Simulations show that, in a neighborhood of the bifurcation point, a repelling limit cycle appears on the low side of the critical parameter value (see Fig. 4). When we increase $\gamma$ beyond this bifurcation point, the stationary state loses its stability and the dynamics are characterized by an unstable spiral. For a higher value of $\gamma$ we find a saddle-node bifurcation at which the lower and the higher stationary states merge in one point. When $\gamma$ increases beyond this critical value, the positive stationary state disappears and the only stationary state is $(0,0)$.

To study the global dynamics of the model we present the phase diagram for $\gamma=0.886$ in the top panel of Fig. 5. There are two intersections of the phase-lines $j($.$) and s($.$) in the positive orthant indicating the presence of two non-zero fixed$ points. The vertical asymptote of $s($.$) is not visible on the chart as it is very close$ to 0 . The situation depicted in this figure displays both a poverty trap and a limit cycle.

Let us first consider two trajectories starting on each side of the limit cycle (traj. 1 and traj. 2 on bottom panel of the figure). They start with the same level of aspirations but the one which starts from inside the cycle has a higher initial level of education. The one that is characterized by slightly lower education spending starts following the same path as the other one, but, diverges from the path leading to the stationary state after three periods and ends by violating the constraint $c_{1 t} \geq \gamma a_{t}$. In this case, the resources of the economy are not sufficient for the adult to consume at least $\gamma a_{t}{ }^{12}$ Hence, starting with too high aspirations or with too low education spending may lead the economy to a poverty trap. This type of dynamics is characterized by sudden take-off episodes leading to a growing gap between economies that were similar at some points.

Consider now the converging trajectory: it is characterized by damped oscillations. This implies that, before reaching its stationary state (balanced growth path), the economy experiences a period with higher growth rates. There is thus overshooting in the growth rate. The interpretation of these oscillations is the following: higher education spending implies higher productivity and higher consumption levels. For the following generation, this leads to higher aspirations that may in turn lead to lower savings in order to maintain the

\footnotetext{
${ }^{12}$ The outcome then depends on what we assume about preferences in this state. For instance, if the consumer is indifferent between all consumption levels that are below the minimum threshold $\gamma a_{t}$, the solution is indeterminate. A complete description of the possible cases is beyond the scope of this paper.
} 

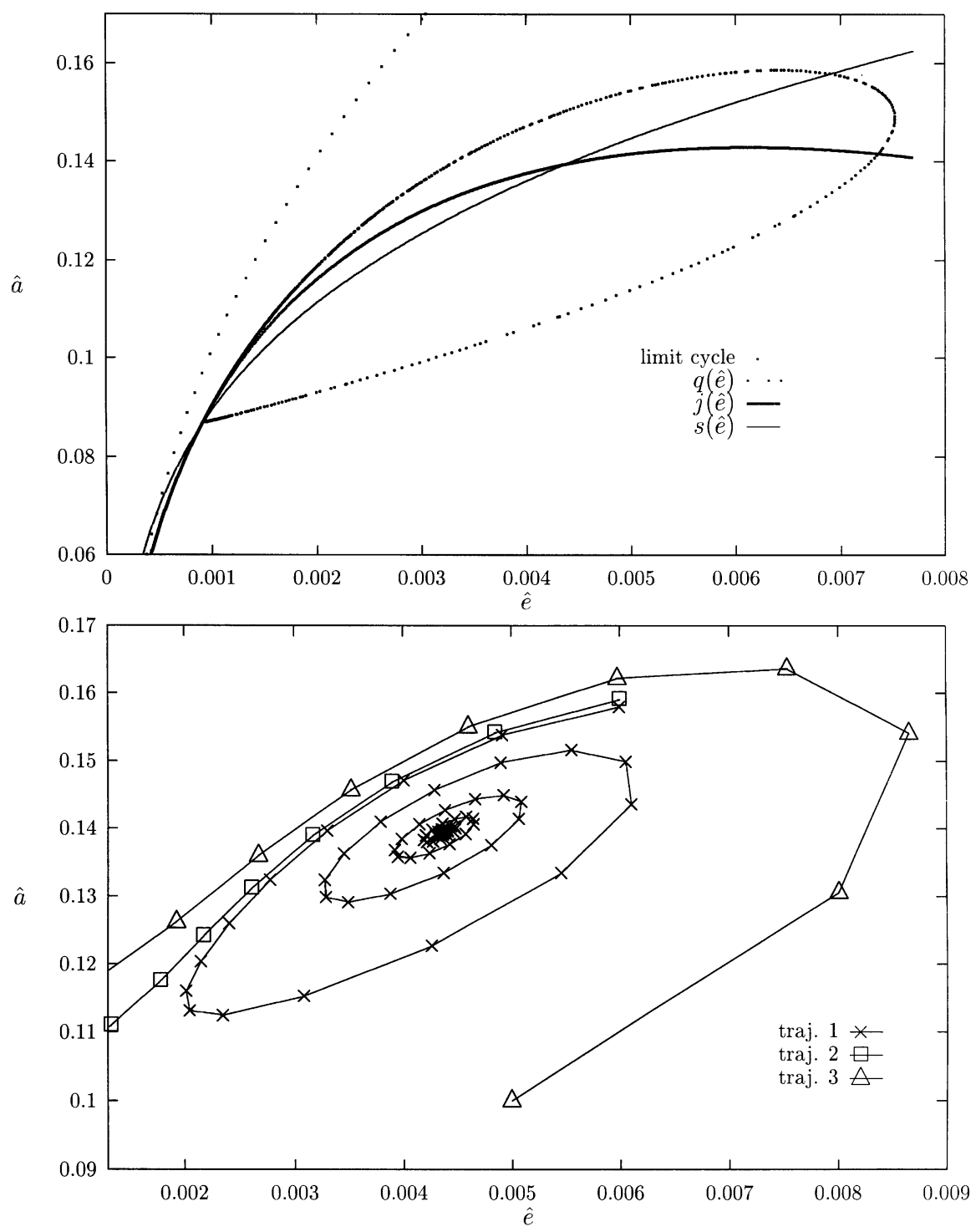

Fig. 5. The phase diagram.

standard-of-living. Lower savings will raise interest rates. When the effect on interest rates dominates the initial effect of education on wages, education spending may fall after a growth period. This lasts until aspirations have reverted to lower levels. 
The limit cycle plotted in the phase diagram is repelling: it defines a basin of attraction for the high-growth stationary state implying that if the initial conditions are located outside the basin, the economy will not reach the high stationary state. This is something like a generalized poverty trap: the range of favorable initial conditions can be very limited.

The role of governments is the general case is much more complicated to analyze than it is in the special case of Section 4.1. Indeed, $\hat{g}$ affects both phase-lines in a non-trivial way, and modifies both the slope and the intercept of the constraint ensuring an interior solution. If we compute the stationary growth rate of the economy as a function of $\hat{g}$, we find again a hump-shaped curve looking like the one presented in Fig. 2.

\section{Discussion}

\subsection{The poverty trap}

One implication of the model is the existence of a poverty trap: for some initial conditions, the economy is led to a no-growth stationary state. This model can thus explain differences in income levels and growth rates across countries in terms of (slight) differences in fundamentals and initial conditions.

The first difference with the existing literature on the subject, surveyed by Benhabib and Gali (1995), Galor (1996) and Azariadis (1996), is that the initial conditions include, in addition to the standard levels of human and/or capital stock variables, an initial level for the stock of norms/aspirations. This model implies that the economies will be divided into two classes as a function of their initial combination of aspirations - human capital: one class experiencing a positive growth rate (that may furthermore oscillate over time) and one class characterized by low or no growth. As our example shows, this dualization may take place even if the initial distribution of initial conditions is concentrated. This is in accordance with the description of convergence proposed by Quah (1996) in which two converge clubs emerge with their own basin of attraction. The presence in one of our examples of a repelling limit cycle reinforces the idea of small basins of convergence around endogenous growth stationary states. Note that the picture proposed by Quah (1996) does not exclude the transition of a poor country to the club of the rich; in our model this would be explained by a favorable initial mix of aspirations and human capital in this poor country.

A second important point to notice is the following: in the existing literature, education below a critical level may lead to a poverty trap and economies starting with a too low stock of human capital may be unable to reach the higher stationary state. This remains true in our framework, yet countries starting with too high education spending may also end in a poverty trap. In that case, the 
high revenues generated by the high human capital stock may rapidly induce a boom and high standard-of-living aspirations. If aspirations rise too rapidly compared to the potentialities of the economy, savings are depressed and investment in education and physical capital drops. This scenario of decline in illustrated in trajectory 3 in Fig. 5.

\subsection{Aspirations and the savings' rate}

One motivation to introduce time non-separabilities in preferences is to improve modelling of the savings behavior (Duesenberry, 1949). In our model, we may compute the equilibrium savings' rate as

$$
\frac{s_{t}}{Y_{t}} \propto \mu-\frac{\gamma \hat{a}_{t}+\hat{g} x\left(\hat{e}_{t}, \hat{g}\right)}{x\left(\hat{e}_{t}, \hat{g}\right)^{1-\alpha} \hat{e}_{t}^{\alpha}} .
$$

On the one hand, the savings' rate is a decreasing function of aspirations at given education spending. On the other hand, the effect of both types of education spending is ambiguous, depending on the magnitude of aspirations. Consequently, someone from a wealthy society will not necessarily have a lower savings' rate than someone from a poorer society as the pure effect of higher aspirations can be offset by other effects linked to the level of education spending and human capital.

\subsection{Oscillations in the growth rate}

One important feature of our model is the presence of oscillations in the growth rate that could either converge, explode or last forever. This is broadly consistent about what we know on growth over a long period of time (see for instance the spectral estimates of the Kondratieff cycle by van Ewijk (1982) and Reijnders (1990) and the study by Solomou (1986)). Finally, note that oscillations are consistent with the stylized fact that growth rates are weakly correlated across decades while country characteristics are stable (Easterly et al., 1993).

\subsection{Can excessively high aspirations slow growth?}

In our model, poverty causes low aspirations which in turn are favorable for growth. Moreover, as shown in the poverty trap examples, excessively high aspirations slow growth. Are there some examples showing that the aspirations effect could indeed be important in the growth process? The decline of Spain in the 16th and 17th centuries is one (see Peaker, 1983), although alternative explanations are plausible too. A more documented example concerns the Golden 1960s in the U.S. and the consecutive recession. In the model, recession periods are preceded by a time of high aspirations, and hence, low satisfaction. If 
the utility level of households were observable, we should observe a drop in utility followed by a drop in the growth rate of the economy. Unfortunately, utility is unobservable, and the proxies we find to measure utility are not available over long periods of time. Easterlin $(1974,1995)$ use the happiness survey carried out by the American Institute of Public Opinion (Gallup) in the years 1946-1970 and by the National Opinion Research Center (University of Michigan) since 1957. The conclusion that can be drawn from the two independent surveys is that there was a decline in happiness between the late 1950s and the mid-1960s. This drop in happiness came in a boom before the drop in growth that started in the mid-1960s, supporting the idea that low happiness (high aspirations) precedes a drop in long-run growth. ${ }^{13}$ Further support of this swing in satisfaction can be found in other surveys reported in Easterlin (1995). This view is also corroborated by the comprehensive study of Campbell (1981) based on 45 happiness surveys. He concludes first that there was a swing in American happiness with a peak in the late 1950s, and second that movements in happiness sometimes occur in direct opposition to what one would have expected on the basis of economic trends.

Further research on the idea that aspirations above a critical level can be a cause of economic stagnation for certain developing countries could be pursued using cross-sectional data. It should first be noted that we do have the adequate data to address this question in a comprehensive way. We have partial pieces of information about personal happiness in some developing countries, thanks to the study of Cantril (1965), that we can compare with the growth performance over the next decades. In Table 1 we gather the results of Cantril's survey on personal happiness with the subsequent growth rate for 10 developing countries. ${ }^{14}$ The 'Personal Happiness' rating has been established following a sophisticated technique designed to make the data comparable across countries. ${ }^{15}$ The simple correlation between the happiness rating and growth in 0.41 (it is equal to 0.67 if we do not take into account the Dominican Republic which experienced prolonged political turmoil at the time of Cantril's survey). There is thus some evidence that the countries which reported the highest level of satisfaction experienced higher growth rate over the following 25 years. This conclusion is obtained without controlling for all the other determinants of growth and we do not know the robustness of the result if one adds other reasonable regressors. Controlling for other effects is however difficult given the very low number of countries for which happiness data are available.

\footnotetext{
${ }^{13}$ We consider here the temporary equilibrium which gives $\hat{e}_{t}$ and $\hat{a}_{t}$ as a function of $\hat{e}_{t-1}$ and $\hat{a}_{t-1}$.

${ }^{14}$ The growth rates have been computed using the data provided in Maddison (1995) and Barro and Sala-I-Martin (1995).

${ }^{15}$ People were asked to imagine the best possible life and the worst possible life which they could lead. They then had to say where their present life fell on a scale from 0 to 10 .
} 
Table 1

Growth 1960-1985 as a function of initial happiness (ca. 1960)

\begin{tabular}{lllllllllll}
\hline & Egypt & Israel & Yugos. & Philip. & Panama & Nigeria & Brazil & Poland & India & Domini. \\
\hline Growth & 2.67 & 2.32 & 2.64 & 1.36 & 2.21 & 1.54 & 2.24 & 1.76 & 1.35 & 1.8 \\
Happiness & 5.5 & 5.3 & 5.2 & 4.9 & 4.8 & 4.8 & 4.6 & 4.4 & 3.7 & 1.6 \\
\hline
\end{tabular}

\section{Conclusion}

This paper considers the effect of rising consumption aspirations in an overlapping generation model in which human capital accumulation is central to account for endogenous growth. More specifically, the utility of consumption depends not on its absolute level, but on its level relative to an aspiration level which itself depends on parents' consumption: the higher the parents' consumption was, the higher is the aspiration level. There is a second intergenerational spill-over via a human capital externality, whereby the higher the parent's human capital is, the higher the return to education expenditures is. In the growth process there are thus two externalities, a positive one linked to the transmission of human capital from one generation to the other and a negative one related to the inheritance of standard-of-living aspirations from their parents. The externalities arise because agents are selfish, thus a generation does not take into account the effect of its decisions on the next generation.

The principal finding is that the interaction of these two externalities leads to rich dynamics. This arises as higher human capital of parents has two competing effects: on the one hand, it increases the incentive to invest in education via the transmission of human capital. On the other hand, a high level of parents' human capital, implying that their consumption is high, lowers the propensity to save of children via the aspiration effect. The dynamics that result depend on the relative strengths of these two effects.

First, there can be poverty traps: an economy with slightly lower initial education or slightly higher aspirations than a critical surface will stagnate whilst one on the other side of the critical surface will grow. This is consistent with the stagnation of an important number of countries at low levels of economic development and with the existence of a growing income gap between certain economies that were similar at some points (Lucas, 1993). The first difference of our model with the existing literature on this subject is that the initial conditions include, in addition to the standard levels of human and/or capital stock variables, an initial level for the stock of norms/aspirations. The second difference is that, under some circumstances, the poverty trap is 
determined by a repelling limit cycle encircling the high-growth stationary state. In that case starting with too high education spending may also lead to a poverty trap: the high revenues generated by the high human capital stock induce very high standard-of-living aspirations; this depresses savings and further leads to a drop in education spending and investment (decline scenario).

Second, oscillations can occur along the growth path. Indeed, in a phase of expansion, there is a point at which the bequest in terms of higher human capital and wages is not sufficient to cover the bequest in terms of higher aspirations. This leads to a drop in savings to maintain the standard-ofliving and induces a recession. When the consecutive impoverishment is strong enough, aspirations have reverted to lower levels and savings may rise again, starting an expansion period. Depending on the relative strength of the two effects and on the current state of the economy compared to its stationary state, this process can either converge, or explode or lead to ever lasting cycles.

Our approach suffers from several limitations. First, the way bequeathed tastes are formalized is a bit drastic: children inherit aspirations, but parents do not care about their children. Presumably such a spill-over comes from social interaction which involves other forms of bequests. In this sense, this resembles the habit formation literature (see e.g. Abel, 1990). If parents care about their children they may restrict consumption to induce their children to save more and avoid recessions (this is shown in a model without human capital in de la Croix and Michel, 1998). Second, since the initial conditions are crucial, we may wonder what kind of history can give rise to combinations in which aspirations are high but the stock of human capital is low. Was the economy perturbed by a huge shock whilst individuals did not adjust their aspirations? A model with several countries and possible interactions between them through norms (e.g. envy) would be helpful in this respect.

The above conclusions are based on an example and are not general. However, it appears clearly that the hypothesis of bequeathed aspirations, which does not seem unrealistic, may have important consequences. Further work is nevertheless needed to assess the influence of aspirations on growth, both theoretically and empirically.

\section{Acknowledgements}

The financial support of the ARC program 'Growth and incentive design' of the Ministry of Scientific Research (French Speaking Community, Belgium) is gratefully acknowledged. I am thankful to C. Azariadis, R. Caminal, F. Collard, A. d'Autume, J. Duran, J.M. Grandmont, P. Michel, A. Mountford, E. Prescott, H. Sneessens, the participants to EEA 97, two anonymous referees and the editor H. Uhlig for their comments on an earlier draft. 


\section{References}

Abel, A., 1990. Asset prices under habit formation and catching up with the Joneses. American Economic Review Papers and Proceedings 80, 38-42.

Azariadis, C., 1996. The economics of poverty traps - part one: Complete markets. Journal of Economic Growth 1, 449-486.

Azariadis, C., Drazen, A., 1990. Threshold externalities in economic development. Quarterly Journal of Economics 101, 501-526.

Barro, R., 1990. Government spending in a simple model of endogenous growth. Journal of Political Economy 98, S103-S125.

Barro, R., 1991. Economic growth in a cross section of countries. Quarterly Journal of Economics 106, 407-443.

Barro, R., Sala-I-Martin, X., 1995. Economic Growth. McGraw-Hill, New York.

Becker, G., 1992. Habits, addictions and traditions. Kyklos 45, 327-345.

Benhabib, J., Gali, J., 1995. On growth and indeterminacy: Some theory and evidence. CarnegieRochester Conference Series on Public Policy 43, 163-211.

Boyd, R., Richerson, P., 1985. Culture and the Evolutionary Process. University of Chicago Press, Chicago, IL.

Brickman, P., Coates, D., Janoff-Belman, R., 1978. Lottery winners and accident victims: Is happiness relative? Journal of Personality and Social Psychology 36, 917-927.

Campbell, A., 1981. The Sens of Well-being in America. McGraw-Hill, New York.

Cantril, H., 1965. The Pattern of Human Concerns. Rutgers University Press, New Brunswick, NJ.

Cavalli-Sforza, L., Feldman, M., 1981. Cultural Transmission and Evolution: A Quantitative Approach. Princeton University Press, Princeton, NJ.

Clark, A., Oswald, A., Warr, P., 1996. Is job satisfaction U-shaped in age? Journal of Occupational and Organizational Psychology 69, 57-81.

Coleman, J., 1990. Foundations of Social Theory. Belknap, Harvard.

de la Croix, D., 1996. The dynamics of bequeathed tastes. Economics Letters 51, 89-96.

de la Croix, D., 1998. Growth and the relativity of satisfaction. Mathematical Social Sciences 36, 105-125.

de la Croix, D., Michel, P., 1998. Altruism and self-refrain. Working Paper, Department of Economics, Université catholique de Louvain, Lonvain-la-Neuve.

de la Croix, D., Michel, P., 1999. Optimal growth when tastes are inherited. Journal of Economic Dynamics and Control 23, 491-518.

de la Croix, D., Monfort, P., 2000. Education funding and regional convergence. Journal of Population Economics.

de la Croix, D., Urbain, J.-P., 1998. Intertemporal substitution in import demand and habit formation. Journal of Applied Econometrics 13, 589-612.

Denison, E., 1974. Accounting for United States Economic Growth, 1929-1969. The Brookings Institution.

Diamond, P., 1965. National debt in a neoclassical growth model. American Economic Review 55, 1126-1150.

Duesenberry, J., 1949. Income, Saving, and the Theory of Consumer Behavior. Harvard University Press, Cambridge, MA.

Easterlin, R., 1971. Does human fertility adjust to the environment? American Economic Review Papers and Proceedings 61, 399-407.

Easterlin, R., 1974. Does economic growth improve the human lot? Some empirical evidence. In: David, P., Reder, M. (Eds.), Nations and Households in Economic Growth. Academic Press, New York.

Easterlin, R., 1995. Will raising the incomes of all increase the happiness of all? Journal of Economic Behavior and Organization 27, 35-46. 
Easterly, W., Kremer, M., Pritchett, L., Summers, L., 1993. Good policy or good luck? Country growth performance and temporary shocks. Journal of Monetary Economics 32, 459-483.

Galor, O., 1996. Convergence? Inferences from theoretical models. The Economic Journal 106, 1056-1069.

Goldin, C., 1994. How America graduated from high school: 1910 to 1960. Working Paper, National Bureau of Economic Research.

Hercowitz, Z., Sampson, M., 1991. Output, growth, the real wage, and employment fluctuations. American Economic Review 81, 1215-1237.

Jones, S., 1984. The Economics of Conformism. Basil Blackwell, Oxford.

Lucas, R., 1988. On the mechanics of economic development. Journal of Monetary Economics 22, $3-42$.

Lucas, R., 1993. Making a miracle. Econometrica 61, 251-272.

Maddison, A., 1995. Monitoring the World Economy 1820-1992. OECD, Paris.

Michalos, A., 1980. Satisfaction and happiness. Social Indicators Research 8, 385-422.

Michel, P., 1993. Overlapping generations models: A tool for macroeconomic analysis. Revue d'Economie Politique 103, 191-220.

Nehru, V., Swanson, E., Dubey, A., 1995. A new database on human capital stock in developing and industrial countries: Sources, methodology and results. Journal of Development Economics 46, 379-401.

Peaker, A., 1983. New found wealth and economic decline in Sixteenth century Spain. National Westminster Bank Quarterly Review 0, 46-54.

Quah, D., 1996. Empirics for economic growth and convergence. European Economic Review 40, 1353-1375.

Reijnders, J., 1990. Long Waves in Economic Development. Elgar, Cheltenham, UK.

Solomou, S., 1986. Non-balanced growth and Kondratieff waves in the world economy, 1850-1913. Journal of Economic History 46, 165-169.

van Ewijk, C., 1982. A spectral analysis of the Kondratieff-cycle. Kyklos 35, 468-499.

Wiggins, S., 1990. Introduction to Applied Nonlinear Dynamic Systems and Chaos. Springer, Berlin. 